\title{
Respiratory symptoms, bronchitis and asthma in children of Central and Eastern Europe
}

\author{
G.S. Leonardi*, D. Houthuijs ${ }^{\#}$, B. Nikiforov`, J. Volf ${ }^{+}$, P. Rudnai ${ }^{\S}$, J. Zejda $^{f}$, E. Gurzau**, \\ E. Fabianova ${ }^{\# \#}$, T. Fletcher*, B. Brunekreef ${ }^{\oplus /}$
}

Respiratory symptoms, bronchitis and asthma in children of Central and Eastern Europe. G.S. Leonardi, D. Houthuijs, B. Nikiforov, J. Volf, P. Rudnai, J. Zejda, E. Gurzau, E. Fabianova, T. Fletcher, B. Brunekreef. (C) ERS Journals Ltd 2002.

ABSTRACT: The multicentre Central European Study of Air Pollution and Respiratory Health (CESAR) aimed to measure the respiratory health of schoolchildren using a standardised questionnaire in six countries of Central and Eastern Europe (CEE), allowing comparisons within this region and with other European countries.

A cross-sectional study was conducted in 25 urban areas of Bulgaria, Czech Republic, Hungary, Poland, Romania, and Slovakia in 1996. Parents of 21,743 schoolchildren of age 7-11 yrs completed a questionnaire based on items from the World Health Organization and International Study of Asthma and Allergies in Childhood questions on cough and wheeze symptoms, as well as on diagnoses by doctors.

Life-time prevalence of bronchitis was $55.9 \%$, asthma $3.9 \%$, and asthmatic, spastic or obstructive bronchitis $12.3 \%$. In CEE countries the prevalence of bronchitis is higher and prevalence of asthma appears lower than in Western Europe. However, if asthma is defined as a diagnosis of either asthma or asthmatic, spastic or obstructive bronchitis, then its prevalence is comparable to Western Europe, or higher.

In this region, within-country variation for most respiratory parameters is less than between-country variation. Between-country comparisons in doctors' diagnoses appear dependent on the choice of definition of asthma. Europe-wide comparisons in prevalence of respiratory symptoms and diagnosis are reported in this study. Some of the EastWest difference in asthma prevalence may be attributable to differences in diagnostic practice.

Eur Respir J 2002; 20: 890-898.

\begin{abstract}
*London School of Hygiene and Tropical Medicine, London, UK. " National Institute of Public Health and the Environment (RIVM), Bilthoven, the Netherlands. National Centre of Hygiene, Sofia, Bulgaria. ${ }^{+}$Regional Institute of Hygiene, Ostrava, Czech Republic. ${ }^{\S}$ National Institute of Environmental Health, Budapest, Hungary. ${ }^{f}$ Institute of Occupational Medicine and Environmental Health, Sosnowiec, Poland. **Environmental Health Centre, Cluj, Romania. "\# State Health Institute, Banska, Bystrica, Slovak Republic. Institute for Risk Assessment Sciences, Utrecht, the Netherlands.
\end{abstract}

Correspondence: G. Leonardi, Environmental Epidemiology Unit, London School of Hygiene and Tropical Medicine, Keppel Street, London, WC1E 7HT, UK.

Fax: 442075804524

E-mail: giovanni.leonardi@1shtm.ac.uk

Keywords: Asthma, bronchitis, Central and Eastern Europe, cross-sectional, prevalence, symptoms

Received: July 172001

Accepted after revision: December 21 2001

The Central European Study of Air Pollution and Respiratory Health (CESAR) was funded by the Commission of the European Communities (CEC): Directorate General XII, Science Research and Development in the framework of the Cooperation with Third Countries and International Organisations research and technological development programme, and Directorate General I, External Economic Relations, in the framework of the financial and technical assistance provided to Central and Eastern Europe (CEE) under the Phare MultiCountry Environment programme.
There is a lack of comparable data on children's respiratory symptoms and conditions across countries of Central and Eastern Europe (CEE countries). This limits investigations into the possible reasons for differences in respiratory health across countries, for example the influence of socioeconomic and environmental factors. Recently, the International Study of
Allergy and Asthma in Childhood (ISAAC) reported on the worldwide prevalence of asthma and related respiratory symptoms [1, 2], and included several CEE countries [3]. Recently, however, no data on prevalence of bronchitis and different types of cough in children were collected using a standard approach in different countries of this region or elsewhere. The 
European Community Respiratory Health Survey [4] involved studies of bronchitis and asthma in adults, and a few other studies compared prevalence of asthma and bronchitis in no more than four countries [5]. East-West comparisons within Europe have been prompted by studies in Germany [6,7], which showed a greater prevalence of asthma and allergy in West Germany. Another study compared respiratory symptoms in 10-12-yr-old schoolchildren from urban Konin in central Poland with both urban and rural parts of Sundsvall in northern Sweden [8]; several respiratory symptoms were reported more frequently among schoolchildren in Poland, while wheezing or diagnosed asthma were more frequent in Sweden. A study in 7-11-yr-old children in two Western and two Eastern European cities found comparable prevalences of lifetime wheezing and higher prevalence of "cough usually" in Poland compared to the UK and the Netherlands [9].

The aim, within the framework of the European Union-funded multicentre Central European Study of Air Pollution and Respiratory Health (CESAR), was to establish comparable baseline data on the respiratory health of primary schoolchildren using a standardised questionnaire in six CEE countries: Bulgaria, Czech Republic, Hungary, Poland, Romania, and Slovakia.

\section{Methods}

A cross-sectional study was conducted in urban areas of Bulgaria, Czech Republic, Hungary, Poland, Romania, and Slovakia in 1996. Ethical approval for the study was obtained in all participating countries. At each phase of the study, training was provided centrally for local operators across all regions, and the same protocols were used in the six countries. Across the whole region, urban areas were selected on the basis of providing contrast in exposure to a range of air pollutants, as described in a previous report [10]. Within each country, four urban areas (five in Hungary) were identified, giving a total of twenty five areas.

In each urban area, 1,000 schoolchildren age 7-11 yrs were identified, sampled from all general primary schools in an area identified on the basis of the following criteria: no major changes in air pollution level in the previous 5-10 yrs, presence of a measurement site of an existing air quality monitoring network, a relative homogeneously exposed population, comparable socioeconomic profile as other study locations, a sufficient number of primary schoolchildren $(>1,500)$, and a relative low rate of migration. Consent for participation was obtained by obtaining signatures from the parent or guardian, except in Bulgaria where consent was obtained verbally at a meeting between parents and school authorities.

This study addressed three main groups of respiratory symptoms: cough, wheeze and shortness of breath. A questionnaire was prepared in English, including items from standard tools: cough items from the World Health Organization (WHO) questionnaire on chronic airflow limitation in children [11], and items on wheeze and hay fever from the ISAAC questionnaire on asthma and allergy in children [12]. Information was also elicited about doctors' diagnoses of asthma, bronchitis, asthmatic, spastic or obstructive bronchitis, and pneumonia. The CESAR items on respiratory symptoms and conditions are reproduced in the Appendix.

Diagnoses of respiratory conditions may vary with doctors' training and cultural preference across European countries. At the time of this study, in addition to the diagnosis of asthma and bronchitis, Central European doctors were known to diagnose "asthmatic bronchitis", "spastic bronchitis", and "obstructive bronchitis". In studies conducted in Germany in the last few years, asthma was defined as any report of "asthma diagnosed by a doctor" or "asthmatic, spastic, or obstructive bronchitis diagnosed by a doctor" [6, 7]. Both these definitions of asthma were used in this study (table 1), to allow comparison to the German studies as well as the ISAAC study, and the prevalence of each was computed separately, as well as the prevalence of asthma defined as a positive answer to either.

Each national research team translated the English version of the questionnaire into their own language, and conducted a pilot study on $\sim 50$ individuals. The translated versions were translated back into English by a group of professional translators in London. Discrepancies were identified between the original and the back-translated English versions, and these were used to change the national versions. A second cycle of back-translations and corrections followed.

The questionnaire was distributed to the children

Table 1.-Definitions of asthma in recent epidemiological studies in schoolchildren

\begin{tabular}{llccc}
\hline & & CESAR study & $\begin{array}{c}\text { Studies by von } \\
\text { MutIUs } \text { et al. [6, 7] }\end{array}$ & $\begin{array}{c}\text { ISAAC study } \\
{[1,13]}\end{array}$ \\
\hline Definition of asthma & $\begin{array}{l}\text { Asthma ever diagnosed } \\
\text { by a doctor } \\
\text { Asthma ever diagnosed by a } \\
\text { doctor or Asthmatic, spastic, } \\
\text { or obstructive bronchitis } \\
\text { ever diagnosed by a doctor }\end{array}$ & Reported & Not reported & Reported \\
& Reported & Not reported \\
\hline
\end{tabular}

CESAR: Central European Study of Air Pollution and Respiratory Health; ISAAC: International Study of Allergy and Asthma in Childhood. 
and completed by a parent, preferably the mother, or guardian. At least two written reminders and several verbal reminders were issued in the following 2-6 weeks. Questionnaires returned to the schools were collected by the investigators, data were entered in a database twice, the two versions compared to identify errors in data entry, which were corrected by checking the originals.

After data entry, new variables were defined: "any cough symptoms", according to which a child who had at least one positive response to any of the cough questions was classified as positive; and similarly for "any wheeze symptoms".

Unadjusted prevalences of respiratory outcomes were computed. Prevalences were also computed, controlled for age and sex; these are not shown as they do not differ significantly from the unadjusted prevalences. The sampling frame in this study includes countries, urban areas, and schools; therefore, the hierarchical structure of the data was taken into account in the computation of confidence intervals (CIs) for the prevalences, using Stata statistical software (procedure "survey") [14]. Point prevalences with their $95 \%$ CIs are illustrated for two of the respiratory end points in figure 1. Prevalence by country was computed to illustrate the mean of the results by country, though it does not represent the prevalence of respiratory disease in the whole country. Between-country and within-country components of prevalence variance were examined by analysis of variance. In a subgroup of 460 children (sampled by randomly selecting school classes) in 19 cities, a study of immune biomarkers was conducted and is reported more fully elsewhere [15]. In these children the presence in serum of specific immunoglobulin (Ig) $\mathrm{E}$ to a mixture of several common aeroallergens (including Dermatophagoides pteronyssinus, Dermatophagoides farinae, cat dander, dog dander and several grasses, trees and moulds of relevance to Central

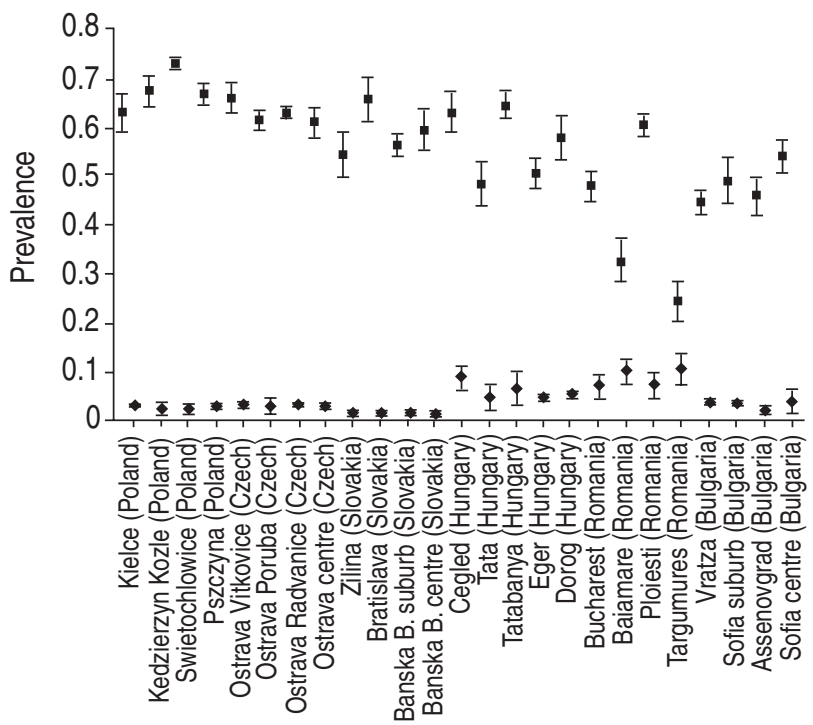

Fig. 1.- Prevalence of bronchitis and asthma ever diagnosed by a doctor in schoolchildren of Central Europe $(n=20,271)$. bronchitis; $\diamond$ : asthma. and Eastern Europe) was determined by multiple radioallergosorbent test (Phadiatop, Pharmacia CAP System), and atopy was defined as a test result $>0.35 \mathrm{kUA} \cdot \mathrm{L}^{-1}$.

\section{Results}

Consent for participation was obtained from 113 of the 114 approached schools. Of 33,051 eligible participants, 21,743 returned a questionnaire $(66 \%)$. Return rates were highest in the areas of Bulgaria $(92 \%)$ and lowest in the areas of the Czech Republic $(55 \%)$. Children of age $<7$ and $>11$ yrs, and children who had moved into the area $<12$ months prior to the study, were originally included in the survey but were excluded from the analysis, bringing the total to 20,271 . The number of participating children per area varied from 526 to 1,106 (mean 811). Information on age, sex, and socioeconomic characteristics of nonresponders was obtained from teachers at school and is comparable to that for responders.

Crude prevalence of respiratory symptoms in the region, and in each country and urban area are shown in table 2 . The highest prevalences of respiratory symptoms across the entire region (mean of six countries) are seen for items capturing events over the whole life of the child, for example $22.6 \%$ for "ever wheezing whistling in the chest at any time in the past", or $21.7 \%$ for "usually cough in the morning in the autumn/winter season". When an item reflects events in the year preceding the data collection, the reported prevalences are lower, $12.7 \%$ in the case of "cough for at least 3 months consecutively in the last autumn/ winter season", 9.3\% for "chest sounded wheezy or whistling in the last 12 months". When a symptom is a reflection of a more specific or more severe respiratory condition, the reported prevalences are lower still, $5.8 \%$ "in the last 12 months chest sounded wheezy during or after exercise", and 3.5\% "attacks of shortness of breath with wheezing in the last 12 months".

Table 2 also shows that the differences in prevalences between countries are large: for example the prevalence of "usually cough in the morning in the autumn/winter season" varies between $6.6 \%$ in Hungary and $46.4 \%$ in Poland, while "ever wheezing whistling in the chest at any time in the past" varies between 12.8\% in Slovakia and 40.8\% in Bulgaria. The observations that did not elicit a response by the person who filled in the questionnaire were classified as missing. The percentage of missing values varied from 1 to $3 \%$ for all symptoms except the question related to sleep disturbance ( $10.8 \%$ missing), the higher value being perhaps attributable to the different format of the question.

Prevalence of reported doctors' diagnosis of asthma, bronchitis and other respiratory conditions, and use of hospital, medical care and medications for respiratory conditions are shown in table 3 . The overall prevalence of doctors' diagnosis across the region was much lower for asthma $(3.9 \%)$ than for bronchitis $(55.9 \%)$. In addition, asthmatic, spastic or obstructive bronchitis $(12.3 \%)$ was much more frequently 


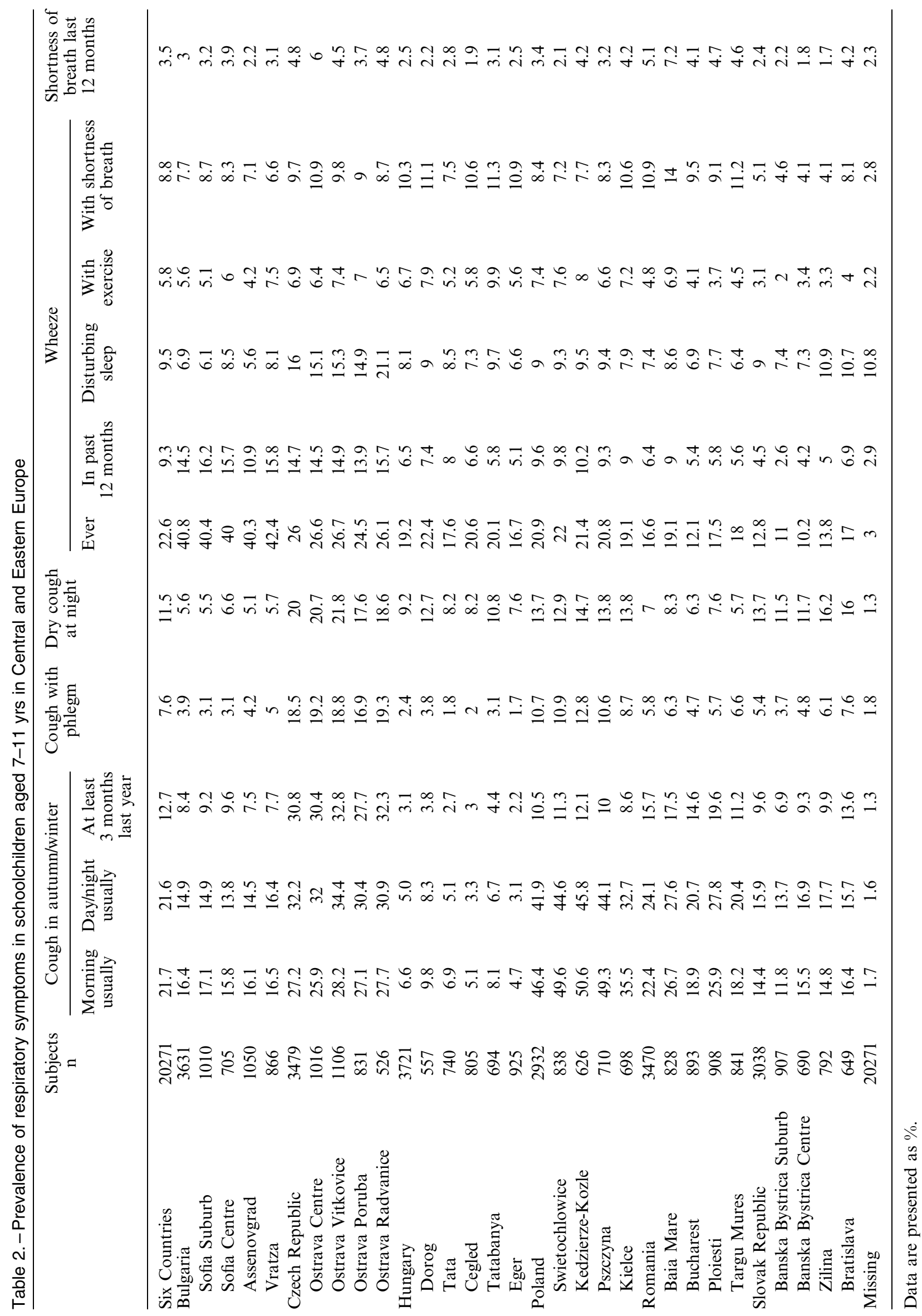




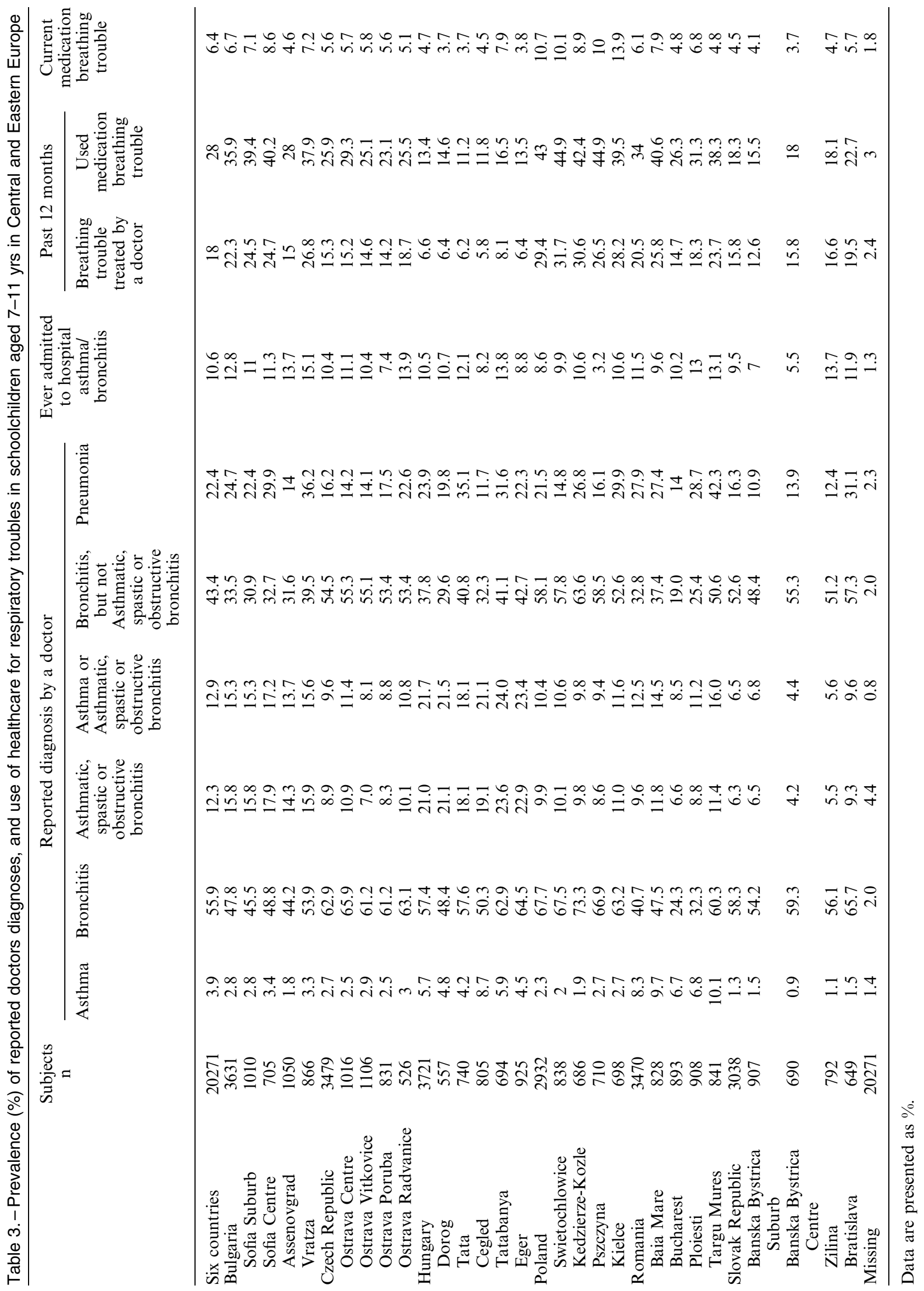


Table 4.-Between-country and within-country variance in respiratory outcome prevalences

\begin{tabular}{lcr}
\hline Respiratory outcome & $\begin{array}{c}\text { Between-country } \\
\text { variance }\end{array}$ & $\begin{array}{c}\text { Within-country } \\
\text { (between-town) variance }\end{array}$ \\
\hline Cough usually in autumn/winter in the morning & 93.9 & 6.1 \\
Cough last autumn/winter for at least 3 months & 95.4 & 4.6 \\
Wheeze in past 12 months & 89.5 & 10.5 \\
Wheeze with shortness of breath & 64.4 & 35.6 \\
Asthma ever diagnosed by a doctor & 84.6 & 15.4 \\
Bronchitis ever diagnosed by a doctor & 61.9 & 38.1 \\
Asthmatic, spastic or obstructive & 90.0 & 10.0 \\
bronchitis ever diagnosed by a doctor & 21.8 & 78.2 \\
Pneumonia ever diagnosed by a doctor & 21.8 & 7 \\
\hline
\end{tabular}

Data are presented as $\%$ of variance.

diagnosed than asthma, though less frequently than pneumonia $(22.4 \%)$.

Table 4 shows results of analysis of variance for a selection of respiratory outcomes. In general, betweencountry variance is larger than within-country variance; the opposite is the case for pneumonia. Figure 1 illustrates prevalence estimates and their 95\% CI for bronchitis and asthma ever diagnosed by a doctor.

\section{Discussion}

The prevalence of lower respiratory symptoms in six CEE countries was computed for 25 populations of young children. The prevalence of reported doctor diagnosis of bronchitis is much higher than asthma in these countries. For most symptoms, between-country differences in prevalence were larger than withincountry (between-area) differences.

The questionnaires in this study were completed by people speaking six different languages. It is possible that some of the difference in prevalence of respiratory symptoms could be attributed to differences in the interpretation of the questions in the six countries $[4,16,17]$. However, in the ISAAC study in 56 countries, there were large variations in prevalence within Spanish and Portuguese-speaking areas as well as English-speaking areas, suggesting that other factors are also likely to be important in determining the prevalence of respiratory symptoms [1]. In the present study, the process of translation from a common form in English into the six languages spoken in this region, and translation back into English identified very few discrepancies in items on respiratory symptoms such as wheezing, suggesting that these languages have an equivalent of "wheezing" as understood by English speakers. A response rate of $66 \%$ may lead to errors in the interpretation of the results if risk factors for respiratory symptoms and conditions have a different prevalence in nonrespondents compared with respondents. The study was unable to survey nonresponders individually; information collected at school level does not indicate large differences in the distribution of age groups and socioeconomic status between nonresponders and responders. Due to both language differences and possible different errors in reported symptoms among responders of different urban areas, caution should be exercised when comparing prevalence of respiratory symptoms across countries. However, standardised questionnaire items were used across the region, and centralised coding and analysis of the data, which permitted better comparisons of prevalence of children's respiratory outcomes between the countries studied than was possible in similar pan-European collaborations in the past $[18,19]$. The number of children surveyed (626 to 1,106 per study area) allowed considerable precision in the estimates of prevalence. A repeatability study in a sample of the children showed a higher degree of reproducibility for doctors' diagnoses than for parent-reported symptoms [20].

Few studies in children are available in the literature. A WHO study in 1980 found a prevalence of cough in the morning of $16.4 \%$ in eight cities of CEE countries, which compares with $21.7 \%$ with a similar question in the present study [18]. In the same areas, cough in the day or night had a prevalence of $23.8 \%$ in the WHO study and $21.6 \%$ in the present study. For comparison, in 11 cities of Western Europe prevalence of cough in the morning and during the day were $12.0 \%$ and $13.1 \%$ [18]. A survey conducted in 1994 found a prevalence of bronchitis ever diagnosed by a doctor of $53.4 \%$ in male children of $7-8$ yrs and $49.2 \%$ in female children 7-8 yrs in Prague, Czech Republic, and in Poznan, Poland $53.2 \%$ in male children $7-10 \mathrm{yrs}$ and $48.8 \%$ in female children $7-10$ yrs $(\mathrm{H}$. Pikhart, Dept of Epidemiology and Public Health, University College London, London, UK, personal communication). In adults, the prevalence of bronchitis diagnosed by a doctor was found to be 4.4-11.7 in Poland [21] and 14.1-18.9 in Prague [22], much lower than in the children of the present study. The results presented here suggest similar high prevalences of cough and bronchitis in CEE countries as in earlier local studies; and higher than in Western Europe.

The prevalence of asthma ever diagnosed by a doctor in children has been reported by several investigators and varies between 1.2 in Slovakia [23], 1.6-2.5 in Romania [24], 1.3-3.5 in Poland [25] and 1.9 in Hungary [26]. When symptoms related to asthma, such as ever wheezing are considered, the prevalences are consistently higher varying between 2.6-5.9 in Romania [3] and 17.1-21.4 in Poland [25]. When bronchial hyperresponsiveness is considered, the prevalence is also higher, 12.5 in Poland [27]. The wording of items on wheezing and asthma has differed 
considerably between surveys, necessitating great care when attempting comparisons between surveys and countries.

The ISAAC study reported prevalence of wheeze symptoms and asthma diagnosed by a doctor in 6-7yr-old children [1, 13]; in the present study several items were included with identical wording as in the ISAAC study, allowing a comparison. Prevalence of asthma diagnosed by a doctor in children of age 6-7 yrs ranges between 1.3 and 4.5 in the CEE countries included in the ISAAC study (Germany, Poland, Estonia, Latvia, Albania and Georgia); this largely overlaps with the prevalence of asthma diagnosis (first definition in table 1) in the present study. There was very little contrast in prevalence by age in the present study: the prevalence of asthma restricted to 7-yr-old children was 3.9.

Studies by vON Mutius and coworkers [6, 7] in Germany report a prevalence of asthma ever of 9.3 in Munich and 7.3 in Leipzig; both these values are higher than the present study's mean estimate of 3.9 for asthma ever (using the first definition in table 1), but lower than the present study's mean estimate of 12.9 for asthma ever (using the second definition in table 1) in six CEE countries.

Underdiagnosis of asthma has been described with reference to asthma-like symptoms accompanied by one or more obstructive airway abnormalities [28]. In the UK, asthma symptoms as defined by the ISAAC questionnaire were accompanied by reported doctors' diagnosis of asthma in $66.2 \%$ of cases [29]. Strikingly, in the present study, only $13.3 \%$ of children who had ever had parent-reported wheeze in their lifetime also had had asthma diagnosed by a doctor in the same period. However, of those who had reported wheeze but not a diagnosis of asthma, $84.4 \%$ reported a diagnosis of bronchitis, and $28.2 \%$ a diagnosis of asthmatic, spastic or obstructive bronchitis. Several explanations can be offered for these findings: one possible interpretation is that the present authors observed underdiagnosis of respiratory conditions in CEE countries when compared with practice in Western Europe. It is also possible that the content of the diagnostic labels "asthma" and "bronchitis" differs somewhat between CEE countries and Western Europe. Though the label "asthma" appears to have been used less frequently in the countries studied here compared to Western Europe, other respiratory diagnoses (bronchitis of various types) were used in the majority of children with respiratory symptoms. The high prevalence of bronchitis may reflect a low threshold in primary care settings for labelling a child with any cough with a diagnosis of bronchitis. However, this is unlikely to apply to children with a diagnosis of asthmatic, spastic or obstructive bronchitis. Past studies have reported large differences between the prevalence of asthma in Western and Eastern Europe [30, 31]. The present results indicate that some of the East-West differences in prevalence of asthma may not be entirely a reflection of differences in morbidity.

In the last few decades, there has been a debate about the appropriateness of distinguishing one or more entities within the collection of wheezy syndromes in school-aged children. Some authors, especially in the 1980s, have advocated the idea that for the purpose of both diagnosis and treatment in this age group, all wheezy children should be treated as asthmatics [32, 33]. Others have supported the idea that a distinction should be made between wheezing triggered only by infection ("wheezy bronchitis") and wheezing which can be triggered by other factors ("allergic asthma") [34], and that the two conditions have different causes [35] and outcomes [36]. In CEE countries, a similar, but possibly not identical, distinction has been common practice, for example according to Bulgarian paediatricians (table 5).

Given the potential value of atopy in distinguishing between different wheezy syndromes in children, the prevalence of asthma by atopic status defined by presence of specific IgE in serum was estimated (table 6). The proportion of atopic children is higher

Table 5. - Differential diagnosis of bronchial asthma and obstructive (spastic, asthmatoid) bronchitis in Bulgaria

\begin{tabular}{|c|c|c|}
\hline Criteria & $\begin{array}{l}\text { Obstructive } \\
\text { bronchitis }\end{array}$ & $\begin{array}{l}\text { Bronchial } \\
\text { asthma }\end{array}$ \\
\hline Beginning & Gradual & Acute and abrup \\
\hline Infectious syndrome & Well manifested & Usually lacking \\
\hline Allergic symptoms & Rare & Frequent \\
\hline Family history & Rare & Frequent \\
\hline Laboratory tests & Nonspecific & $\begin{array}{l}\text { Eosinophilia } \\
\text { and high IgE }\end{array}$ \\
\hline Complications & $\begin{array}{l}\text { Relatively } \\
\text { frequent, } \\
\text { pneumonia }\end{array}$ & Rare \\
\hline Prognosis & Good & $\begin{array}{l}50 \% \text { recover } \\
\text { at puberty }\end{array}$ \\
\hline
\end{tabular}

IgE: immunoglobulin E.

Table 6.-Prevalence of respiratory symptoms and diagnoses by atopic status measured by a screening test for multiple specific immunoglobulin $E$ against aeroallergens $(n=460)$

\begin{tabular}{lcc}
\hline & $\begin{array}{c}\text { Prevalence } \\
\%\end{array}$ & $\begin{array}{c}\text { Number of } \\
\text { participants }\end{array}$ \\
\hline Asthma & & \\
Atopic & 2.8 & 12 \\
Nonatopic & 1.2 & 5 \\
All & 4.0 & 17 \\
Asthmatic, spastic or & & \\
obstructive bronchitis & 3.7 & 15 \\
$\quad$ Atopic & 7.1 & 29 \\
Nonatopic & 10.8 & 44 \\
All & 16.9 & 71 \\
Bronchitis & 40.4 & 170 \\
Atopic & 57.3 & 241 \\
Nonatopic & & \\
All & 10.3 & 40 \\
Any wheeze symptoms & 22.2 & 86 \\
Atopic & 32.5 & 126 \\
Nonatopic & & \\
All & 9.5 & 40 \\
Any cough symptoms & 27.1 & 114 \\
Atopic & 36.6 & 154 \\
Nonatopic & & \\
All & & \\
\hline
\end{tabular}


in those diagnosed with "asthma" (12 out of $17=$ $70.6 \%)$ and smaller in those diagnosed with "asthmatic, spastic or obstructive bronchitis" (15 out of $44=34.1 \%$ ). This would support the idea that the two diagnostic labels discriminate between allergic asthma and wheezy bronchitis. However, the discrimination is not very good, as the actual number of atopic children is higher among those with "asthmatic, spastic or obstructive bronchitis" than those with asthma. In addition, children diagnosed with "bronchitis" are often positive to a test for atopy ( 71 out of $241=$ $29.5 \%$ ). Therefore, from the data a distinction between asthma, wheezy bronchitis and bronchitis cannot be made simply on the basis of atopic status.

In Central and Eastern European countries, bronchitis is a more prevalent diagnosis than asthma. Prevalence of bronchitis is much higher in these countries than Western Europe. Prevalence of asthma appears lower in Central and Eastern European countries than Western Europe; however most or all of the difference may be attributable to diagnostic practice in Central and Eastern European countries, where "bronchitis", and in particular asthmatic, spastic or obstructive bronchitis, may have been used for children, when in Western Europe asthma would have been diagnosed. In this region, withincountry variation for most respiratory parameters is less than between-country variation. Between-country comparisons in doctors' diagnoses appear dependent on the choice of definition of asthma.

\section{Appendix: questions about the child's health in the CESAR study}

1) Items on cough:

1.1 Does this child usually cough in the morning in autumn/winter season? yes/no 1.2 Does this child usually cough during the day or at night in autumn/winter season? yes/no 1.3 Did this child cough on most days for at least 3 months consecutively in the last autumn/winter season? yes/no 1.4 Does this child usually seem congested in the chest or cough up phlegm (mucus) when he/she does not have a cold?

yes/no

1.5 Has this child had a dry cough at night in the last 12 months, apart from coughing with a cold or chest infection?

yes/no

2) Items on wheeze:

2.1 Has this child ever had wheezing or whistling in the chest at any time in the past? yes/no If you responded "yes" to question 2.1 continue to question 2.2; otherwise continue to question 2.3.

2.2 Has the child's chest sounded wheezy or whistling in the last 12 months?

yes/no

2.3 In the last 12 months, how often, on average, has this child's sleep been disturbed due to wheezing?

Never woken with wheezing [ ]

Less than one night per week [ ]

One or more nights per week [ ]

2.4 In the last 12 months, has this child's chest sounded wheezy during or after exercise? yes/no
2.5 Has this child ever had attacks of shortness of breath with wheezing? yes/no If you responded "yes" to question 2.5 continue to questions 2.6 and 2.7; otherwise continue to question 3.1.

2.6 Has this child had attacks of shortness of breath with wheezing in the last 12 months? yes/no 2.7 How many times did this happen in the last 12 months?

None [ ]

1 to 3 [ ]

4 to 12[]

$>12$ [ ]

3) Doctors' diagnoses:

3.1 Has the child ever had asthma, diagnosed by a doctor? yes/no

3.2 Has the child ever had bronchitis, diagnosed by a doctor? yes/no

3.3 Has this child ever had asthmatic, spastic or obstructive bronchitis, diagnosed by a doctor? yes/no 3.4 Has the child ever had pneumonia, diagnosed by a doctor?

yes/no

\begin{abstract}
Acknowledgements. The authors thank the participating children and parents, and the people who helped the study including teachers, doctors and nurses who helped collect the data. The authors are grateful to $\mathrm{O}$. Breugelmans and W. Roemer for assistance in the data management, and to B. Armstrong and S. Pattenden for statistical advice, and to all the staff in each of the national research teams who worked on the survey organisation and data management for this project. Contributors: E. Lebret, T. Fletcher, D. Houthuijs and B. Brunekreef originally designed and supervised the overall CESAR study; D. Houthuijs further developed the design and provided coordination of the implementation, with assistance from G. Leonardi. Design, execution, and data management were agreed among all six participating countries national research teams and the coordinating centres in the Netherlands and the UK. G. Leonardi analysed the data and prepared the manuscript, with contributions by several of the co-authors.

The six national research teams were composed as follows: B. Nikiforov, T. Antova, B. Boeva (Bulgaria); J. Volf, H. Slachtova, I. Tomasek, A. Splichalova (Czech Republic); P. Rudnai, I. Farkas, A. Páldy (Hungary); J. Zejda, R. Zlotkowska, B. Jazwiec-Kanyion (Poland); E. Gurzau, C. Marinescu, E.M. Niciu, S. Surdu (Romania); E. Fabiánová, M. Pernisová, K. Slotová, F. Hruba (Slovakia).
\end{abstract}

\section{References}

1. ISAAC. Worldwide variations in the prevalence of asthma symptoms: the International Study of Asthma and Allergies in Childhood (ISAAC). Eur Respir $J$ 1998; 12: 315-335.

2. Pearce N, Weiland S, Keil U, et al. Self-reported prevalence of asthma symptoms in children in Australia, England, Germany and New Zealand: An 
international comparison using the ISAAC protocol. Eur Respir J 1993; 6: 1455-1461.

3. Björkstén B, Dumitrascu D, Foucard $\mathrm{T}$, et al. Prevalence of childhood asthma, rhinitis and eczema in Scandinavia and Eastern Europe. Eur Respir $J$ 1998; 12: 432-437.

4. European Community Respiratory Health Survey. Variations in the prevalence of respiratory symptoms, self-reported asthma attacks, and use of asthma medication in the European Community Respiratory Health Survey (ECRHS). Eur Respir J 1996; 9: 687-695.

5. Burr ML, Limb ES, Andrae S, Barry DMJ, Nagel F. Childhood asthma in four countries: a compative survey. Int $J$ Epidemiol 1994; 23: 341-347.

6. von Mutius E, Martinez FD, Fritzsch C, Nicolai T, Roell G, Thiemann HH. Prevalence of asthma and atopy in two areas of West and East Germany. Am J Respir Crit Care Med 1994; 149: 358-364.

7. von Mutius E, Fritzsch C, Weiland SK, Roll G, Magnussen $H$. Prevalence of asthma and allergic disorders among children in united Germany: a descriptive comparison. BMJ 1992; 305: 1395-1399.

8. Bråbäck L, Breborowicz A, Dreborg S, Knutsson A, Pieklik H, Björkstén B. Atopic sensitization and respiratory symptoms among Polish and Swedish schoolchildren. Clin Exp Allergy 1994; 24: 826-835.

9. Fischer PH, Kriz B, Martuzzi M, et al. Risk factors indoors and prevalences of childhood respiratory health in four countries in Western and Central Europe. Indoor Air 1998; 8: 244-254.

10. Houthuijs D, Breugelmans O, Hoek G, et al. PM10 and PM2.5 concentrations in Central and Eastern Europe: results from the CESAR study. Atmosph Environm 2001; 35: 2757-2771.

11. Florey CDV, Leeder SRE. Methods for cohort studies of chronic airflow limitation. Copenhagen, Denmark, WHO Regional Publications, European Series No. 12, 1982.

12. Asher MI, Keil U, Anderson HR, et al. International Study of Asthma and Allergies in Childhood (ISAAC): rationale and methods. Eur Respir J 1995; 8: 483-491.

13. Duhme H, Weiland SK, Rudolph P, Wienke A, Kramer A, Keil U. Asthma and allergies among children in West and East Germany: a comparison between Munster and Greifswald using the ISAAC phase I protocol. International Study of Asthma and Allergies in Childhood. Eur Respir J 1998; 11: 840-847.

14. Stata Corp. Stata Statistical Software: Release 6.0. College Station, TX, Stata Corp, 1999.

15. Leonardi GS, Houthuijs D, Steerenberg PA, et al. Immune biomarkers in relation to exposure to particulate matter: a cross-sectional survey in seventeen cities of central Europe. Inhal Toxicol 2000; 12: Suppl. 4, 1-14.

16. Pekkanen J, Remes ST, Husman T, et al. Prevalence of asthma symptoms in video and written questionnaires among children in four regions of Finland. Eur Respir J 1997; 10: 1787-1794.

17. Osterman J, Armstrong BG, Ledoux E, Sloan M, Ernst P. Comparison of French and English versions of the ATS respiratory questionnaire in a bilingual working population. Int J Epidemiol 1991; 20: 138-153.

18. Colley JRT, Brasser LJ. Chronic respiratory diseases in children in relation to air pollution. Report on a WHO study. Copenhagen, Regional Office for Europe, World Health Organization, 1980.

19. Florey CD, Swan AV, van der Lende R, Holland WW, Berlin A, Di Ferrante E. Report on the EC epidemiological survey on the relationship between air pollution and respiratory health in primary schoolchildren. Brussels, Commission of the European Communities, Environmental Research Programme, 1983.

20. Jazwiec-Kanyion B, Zlotkowska R, Zejda J. Repeatability of answers in questionnaire investigation of respiratory tract symptoms in children (in Polish). Pneum i Alergologia Polska 1998; 66: 459-463.

21. Nikodemowicz E. Environmental pollution with tobacco smoke-a threat to human health. Principles for prevention of tobacco smoking (in Polish). Folia Medica Cracoviensia 1993; 34: 179-186.

22. Vondra V, Reisova M, Prazakova J, et al. Prevalence of bronchial asthma, chronic bronchitis and bronchial hyperreactivity in the adult population in the Prague 8 district (in Czech). Casopis Lekaru Ceskych 1993; 132: 113-118.

23. Kopriva F, Souskova E. Epidemiology of bronchial asthma in children in Olomouc district. Acta Universitatis Palackianae Olomucensis Facultatis Medicae 1994; 138: 33-34.

24. Popescu IG, Mazilu M, Jianu E, Banescu O, Nastase C. Study of the incidence and prevalence of children bronchial asthma in a Romanian town. Medecine Interne 1977; 15: 35-40.

25. Zejda JE, Skiba M, Orawiec A, Dybowska T, Cimander B. Respiratory symptoms in children of Upper Silesia, Poland cross-sectional study in two towns of different air pollution levels. Eur J Epidemiol 1996; 12: 115-120.

26. Endre L. Increasing frequency of childhood asthma in Hungary and other countries, and the possible role of air pollution. International Rev Allergol Clin Immunol 1996; 2: 74-79.

27. Lis G, Pietrzyk JJ. Response-dose ratio as an index of bronchial responsiveness to hypertonic saline challenge in an epidemiological survey of asthma in Polish children. Ped Pulmonol 1998; 25: 375-382.

28. Siersted HC, Boldsen J, Hansen HS, Mostgaard G, Hyldebrandt N. Population based study of risk factors for underdiagnosis of asthma in adolescence: Odense schoolchild study. BMJ 1998; 316: 651-655.

29. Kaur B, Anderson HR, Austin J, et al. Prevalence of asthma symptoms, diagnosis, and treatment in 12-14 year old children across Great Britain (international study of asthma and allergies in childhood, ISAAC UK). BMJ 1998; 316: 118-124.

30. Bråbäck L. Risk factors for atopy and asthma among schoolchildren: experiences from comparisons between Eastern and Western Europe. Eur Respir Rev 2000; 10 : 408-410.

31. Weiland SK, von Mutius E, Hirsch T, et al. Prevalence of respiratory and atopic disorders among children in the East and West of Germany five years after unification. Eur Respir J 1999; 14: 862-870.

32. Speight ANP, Lee D, Hey EN. Underdiagnosis and undertreatment of asthma in childhood. BMJ 1983; 286: $1253-1256$.

33. Lee DA, Winslow NR, Speight ANP, Hey EN. Prevalence and spectrum of asthma in childhood. BMJ 1983; 286: 1256-1258.

34. Strachan DP. Early British studies of chronic respiratory disease and their current relevance. Eur Respir Monographs 2000; 15: 2336.

35. Ross S. Asthma trends: Causes of wheeze and asthma may differ. $B M J$ 1994; 309: 603.

36. Ross S, Godden D, McMurray D, et al. Social effects of wheeze in childhood: A 25 year follow up. $B M J$ 1992; 305: 545-548. 